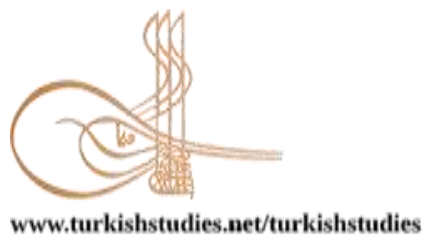

Turkish Studies

\title{
COVID 19 Pandemisinin Finansal Etkileri: BİST İmalat Sektörü Uygulaması
}

Financial Effects of COVID 19 Pandemic: Application of BIST Manufacturing Sector

\author{
Ahmet Bayraktar*
}

\begin{abstract}
COVID19 first time in December 2019 in Wuhan province in China, first in Turkey on March 11, 2020 is beyond many social, political and economic impact was. Especially international restrictions within the framework of quarantine practices and interruptions in supply chains led to a contraction in economic activities. During this period, investments in some sectors decreased and demand cases were announced, especially in the food sector. After COVID 19 was described as a pandemic, there was an increase in only one health problem. With the pandemic, sales in stock markets lowered stock prices. In the following period, a recovery movement was observed in the stock markets. In this study, the effect of Covid 19 pandemic on BIST Manufacturing Sector stocks was examined. According to the stock return results, it is seen that the stocks of the manufacturing sector, which are traded in BIST 100, produce negative returns on average on a daily basis. The said return is more noticeable one day after the announcement date $(\mathrm{Dt}+1:-0.07)$. On this date, there was a decrease in BIST in parallel with the decrease seen in the world stock markets due to the pandemic effect. In the research, it has been observed that in the uncertainty environment created by the pandemic, price volatility is high, especially around the date of the Announcement. When the research data are analyzed on a process basis, it is seen that it produced an average of $0.12 \%$ in the period 130 days before the announcement date (Dt-130), and an average of $0.46 \%$ positive return in the 130 days after the announcement date $(\mathrm{Dt}+130)$. According to these data, it is seen that the manufacturing sector stocks traded in the BIST 100 generate higher returns than the period before the pandemic. These data are interpreted as the sector eliminated the negative effects of the pandemic and recovered on the basis of BIST.
\end{abstract}

Structured Abstract: The COVID-19 Pandemic, which emerged in China towards the end of 2019, started to be seen in Turkey in March. With the geographical spread of the pandemic, it has affected many countries and sectors directly and indirectly. This effect still continues. Apart from being a health problem, the pandemic also affects countries economically. With the restrictions and social isolation practices, tourism, transportation, sports and education have been the sectors most affected by the pandemic. The food sector, on the other hand, faced a sudden and intense demand during this period. Another sector affected by the pandemic was the manufacturing sector. Especially with the restriction of international transportation, the disruptions in the supply chains have adversely affected the manufacturing sector. Similarly, stock markets have been one of the sectors most affected by the pandemic. The aim of the study is to determine how the stocks of companies operating in the BIST manufacturing sector are affected by the pandemic.

\footnotetext{
*Dr. Öğr. Üyesi, Aksaray Üniversitesi, SBMYO, Muhasebe ve Vergi Bölümü Asst. Prof Dr., Aksaray University, VSSS, Department of Accounting and Tax ORCID 0000-0002-2616-0825

ahmetbayraktar61@yahoo.com

Cite as/ Atıf: Bayraktar, A. (2020). COVID 19 pandemisinin finansal etkileri: BİST imalat sektörü uygulaması. Turkish Studies, 15(8), 3415-3427. https://dx.doi.org/10.7827/TurkishStudies.46807

Received/Geliş: 08 October/Ekim 2020

Accepted/Kabul: 20 December/Aralık 2020

Copyright $($ ) MDE, Turkey
} 
As the COVID-19 Pandemic news increased, this situation caused panic globally and brought the global economy to a halt. Global financial market risks, especially systematic risk, have increased significantly with the pandemic. The uncertainty and financial losses caused by the pandemic caused the markets to become highly unpredictable. With COVID-19, the volatility of stocks has increased in financial markets. In this process, the expectation that the announcement of social distance measures will have a negative impact on economic activities negatively affected stock market returns.

According to the results of the study, it is seen that the stocks of the manufacturing sector traded in BIST 100 produced negative returns on average on a daily basis. The said return is more noticeable one day after the announcement date $(\mathrm{Dt}+1:-0.07)$. On this date, there was a decrease in BIST in parallel with the decrease seen in the world stock markets due to the pandemic effect. In the study, it was observed that in the uncertainty environment created by the pandemic, similar to the data obtained in literature studies, price volatility was high especially around the date of the Announcement. On the basis of the process, it is seen that in the period 130 days before the announcement date (Dt-130), it produced an average of $0.12 \%$, and in the 130 days after the announcement date $(\mathrm{Dt}+130)$, it produced an average of $0.46 \%$ positive return. The results obtained are also statistically significant. According to these data, it is seen that the manufacturing sector stocks traded in the BIST 100 generate higher returns than the period before the pandemic. These data are interpreted as the sector eliminated the negative effects of the pandemic and recovered on the basis of BIST. At this point, it is thought that the demands of the new investors who joined the market during the pandemic process for the BIST 100 Manufacturing sector stocks are effective. In addition, it can be said that the depth of the sector stocks, strong stocks, is also effective. Investor risk appetite is also considered as another important factor. In addition, it can be said that the funds transferred to the markets during the COVID 19 process are directed to the stock market. This is thought to have an impact on the performance of the manufacturing sector stocks. However, the uncertainty continues with the recovery in stock markets, which prevents the stock markets from rising. Foreign investor outflow from BIST is increasing, at this point, it is necessary to ensure that economic policies are sustainable and increase direct and portfolio investments, especially by providing trust in foreign investors.

In general, it can be said that there is a positive process in the markets as of October. However, inflation increases with the effect of the increase in exchange rates, the depreciation of the TL negatively affects the import-export balance, and increases the production input costs. Also, second wave expectations create uncertainty in the markets. Therefore, the positive economic process experienced is defined as recovery and it is thought to be early for normalization. In general, it can be said that there is a decrease in the export revenues of the countries during the pandemic process. In a period where global economies are negatively affected, it becomes difficult to export. Therefore, with new technology-intensive investments, it is necessary to increase exports by producing products with high brand value. In addition, reducing foreign dependency in energy is considered as an important factor for a strong economy. At this point, it is thought that the newly discovered energy reserves will positively affect the sector in the future. Similarly, supply chains are negatively affected due to the restrictions of countries in transportation due to the COVID-19 pandemic, so it is clear that reducing international restrictions will affect the sector positively.

When the performance of the manufacturing sector stocks is evaluated within the framework of PMI data, the sector that contracted in the second quarter of the year with the impact of COVID-19 shows that the economy will show a growth performance in general due to the positive data in the third quarter. In addition, the capacity utilization rate in the sector increased in the third quarter. The data announced are interpreted as the sector reduced the negative effects of the pandemic, provided employment and growth, and therefore it will continue to improve. It is clear that this situation will positively affect the performance of the sector stocks. Considering that the sector is in a recovery period, it is important for individual investors to make medium and long term investments rather than short term. Also, when purchasing stocks, it is necessary to analyze their real value and growth potential. The quality, risks and past performances of the stocks should be considered as important factors.

Keywords: Finance, COVID 19, BIST, Manufacturing Sector, Stock Return

Öz: COVID 19 ilk olarak Çin Wuhan eyaletinde Aralık 2019 ayında tespit edildi, Türkiye'de ise 11 Mart 2020 tarihinde ilk vaka duyuruldu. COVID 19 pandemi olarak nitelendirilmesinden sonra sadece bir sağlik sorunu olmasının ötesinde birçok sosyal, siyasal ve ekonomik etkileri oldu. Özellikle karantina uygulamaları çerçevesinde uluslararası sınırlandırmalar ile birlikte tedarik zincirlerindeki kesintiler ekonomik faaliyetlerde 
daralmaya yol açtı. Bu süreçte bazı sektörlerde yatırımlar azaldı ve özellikle gıda sektöründe talep artışı görüldü. Pandemiyle birlikte menkul kıymet borsalarında satışlar hisse senedi fiyatlarını düşürdü. Daha sonraki süreçte ise borsalarda toparlanma hareketi gözlendi. Bu çalışmada BİST İmalat Sektörü hisse senetleri üzerinde COVID 19 pandemisinin etkisi incelenmiştir. Hisse senedi getiri sonuçlarına göre, BİST 100'de işlem gören İmalat sektörüne ait hisse senetlerinin gün bazında ortalama olarak negatif getiri ürettikleri görülmektedir. Söz konusu getiri duyuru tarihinden bir gün sonrasında daha belirgindir (Dt+1: $-0,07)$. Bu tarihte pandemi etkisiyle Dünya borsalarında görülen düşüşe paralel BİST’te de düşüş gerçekleşmiştir. Araştırmada pandeminin yarattığı belirsizlik ortamında özellikle Duyuru tarihi etrafında fiyat oynaklığının yüksek olduğu gözlemlenmiştir. Araştırma verileri süreç bazında incelendiğinde ise duyuru tarihinden 130 gün önceki süreçte (Dt-130) ortalama olarak \%0,12, duyuru tarihinden sonraki 130 günlük süreçte (Dt+130) ortalama olarak \%0,46 pozitif getiri ürettiği görülmektedir. Bu verilere göre BİST 100 de işlem gören imalat sektörü hisse senetlerinin pandemiden önceki süreçten daha fazla getiri ürettikleri görülmektedir. Bu veriler BİST bazında sektörün pandeminin olumsuz etkilerini giderdiği ve toparlandığı şeklinde yorumlanmaktadır.

Anahtar Kelimeler: Finans, COVID 19, BİST, İmalat Sektörü, Hisse Senedi Getirisi

\section{Giriş}

COVID-19 ilk olarak Çin'in Wuhan eyaletinde Aralık 2019, Türkiye'de ise 11 Mart 2020 tarihinde duyurulmuştur. COVID-19 Dünya Sağlık Örgütü tarafından pandemi olarak nitelendirilmesinden sonra sadece bir sağlık sorunu olmasının ötesinde birçok sosyal ve ekonomik etkileri olmuştur. Özellikle karantina uygulamaları çeçevesinde sosyal izolasyon ve uluslararsı sinırlandırmalar ile birlikte ülkeleri etkilemeye başlamıştır. Uluslararsı tedarik zincirlerindeki kesintiler ekonomik faaliyetlerde daralmaya yol açmıştır. Bu süreçte bazı sektörlerde yatırımlar azalmış, bununla birlikte özellikle gıda sektöründe talep artışı görülmüştür.

COVID-19 küresel olarak toplumları, işletmeleri, devletleri dolaylı olarak da finansal piyasaları ve küresel ekonomiyi etkilemeye devam etmektedir. Hükümetlerin önlemleri ve sınırlandırmaları tedarik zincirlerinde kesintilere yol açmasının yanısıra sermaye piyasalarını da etkilemektedir. McKibbin \& Fernando (2020)'nin belirttiği gibi, genel olarak, pandemilerin oluşturduğu şoklar, tüketim ve yatırımlarda keskin bir düşüşe neden olmaktadır. Toplam talepteki düşüş, risk artışları ile birlikte hisse senedi piyasalarında düşüşe neden olmaktadır. Bu süreçte hisse senedi piyasalarında hem risk artışı hem de ekonomik yavaşlama ile birlikte beklenen getiriler azalmakta ve hisse senedi fiyatlarında keskin düşüşler yaşanabilmektedir. Benzer şekilde, Altın (2020) çalışmasında vurguladığı gibi Etkin Piyasalar Hipotezine göre finansal varlık bilgileri elde edilebilir bilgilerin toplamını içermektedir. Piyasaya yeni bilgi ulaştı̆̆ zaman varlık fiyatları hızlı bir şekilde yeni denge durumunda oluşmaktadır. Bu çerçevede pandemiyle birlikte menkul kıymet borsalarında piyasaya ulaşan yeni bilgiden kaynaklanan tepki satışları ilk olarak hisse senedi fiyatlarını düşürmüş, daha sonraki süreçte ise borsalarda kayıplarını telafi etme ve toparlanma hareketi gözlenmiştir. Nicola vd. (2020) çalışma sonuçlarına göre bu süreçte küresel hisse senedi piayasalarındaki düşüş oynaklığı artırmış ve likiditeyi kritik seviyelere getirmiştir. Goodell (2020)'e göre pandemi, aynı zamanda, hemen hemen her ülke genelinde iç talebi de büyük ölçüde etkilemektedir. Kamu ve özel sektör işgücü verimliliğinde azalma, sosyal mesafenin ekonomik aktivitelerde yol açtı̆̆ kayıplarla birlikte doğrudan yabancı yatırımlar üzerinde de etkisi görülmektedir. Ramelli \& Wagner (2020)'e göre ise, pandemi koşullarında yüksek kurumsal borç ve nakit sıkıntısı olan firmaların faaliyetlerini devam ettirebilmeleri güçleşmektedir. Dolayısıyla bu süreçte hisse senedi piyasası katılımcıları pandeminin sağlık sorunu olmasının yanı sıra gerçek ekonomik etkilerini de göz önüne alarak yatırım kararları almaktadır.

\section{Literatür Çalışmaları}

COVID-19 Pandemisinin finansal piyasalar üzerindeki etkilerinin araştırıldığı çalışmalar aşağıda özetlenmektedir: 
Zhang vd. (2020) COVID-19 sürecinin finansal piyasalar üzerindeki etkisinin incelendiği çalışma sonuçlarına göre, pandemiyle birlikte küresel finansal piyasa riskleri önemli ölçüde artmıştır. Ayrıca, bireysel borsa tepkileri, her ülkedeki salgının ciddiyetiyle açıkça bağlantılıdır. Yazarlara göre, pandeminin yol açtığı belirsizlik ortamı ve bununla bağlantılı ekonomik kayıplar, piyasaların oldukça değişken ve öngörülemez hale gelmesine neden olmaktadır.

Ali vd. (2020) Finansal piyasalarda pandemi etkisini araştırdıkları çalışma sonuçlarına göre, COVID-19'un ortaya çıkmasıyla birlikte finansal piyasalarda yüksek oynaklık ve belirsizlik seviyesi artmıştır. Bu süreçte 100 gün içerisinde küresel olarak zenginliğin yüzde 30 azalmıştır. Pandeminin yayılmasıyla birlikte güvenli emtiaların getirileri ABD'de negatife dönmüş, fakat oynaklı̆̆ 1 azalmıştır.

Liu vd. (2020) COVID-19'dan etkilenen başlıca ülkelerin borsaları üzerindeki anlık etkisinin analiz edildiği çalışmada, korkulan bir hastalığın finansal piyasaları üzerindeki beklenmedik salgın etkileri araştıılmıştır. Çalışma sonuçlarına göre: (1) COVID-19 pandemisi, etkilenen tüm ülkelerde ve bölgelerde borsa getirileri üzerinde önemli bir olumsuz etkiye sahiptir. (2) Asya ülkelerinin borsaları pandemiye daha hızlı tepki vermiş ve bazıları salgının ilerleyen safhalarında biraz iyileşmiştir. (3) Onaylanmış COVID-19 vakaları, büyük hisse senedi endekslerinin performansları üzerinde Asya'dakilerle anormal getiriler açısından daha büyük bir düşüşe neden olan önemli olumsuz etkilere sahiptir. (4) Yatırımcının korku duyarlılığının, COVID19 salgınının borsalar üzerindeki etkisi olduğu kanıtlanmıştır. Yazarlara göre, COVID-19 salgını artık bir pandemi haline geldiğinden, yalnızca gelecekteki halk sağlığı sorunlarından kaçınmanın yollarını değil, aynı zamanda finansal sorunları da düşünmemiz gerektirmektedir. Salgın korkusu ve hastalık bulaşmasını kontrol etmeye yönelik politika önlemleri, özellikle emek yoğun ve imalat sektöründe küresel bir arz şokuna katkıda bulunmuştur. Hisse senedi fiyatları gelecekteki kazançların potansiyelini temsil ediyor ve yatırımcılar salgını ekonomik faaliyetlerin azalması olarak görüyor ve gelecekteki gelirlerle ilgileniyorlar. Yazarlara göre, bu süreçte normal yatırımciların tepkisi hisse senetlerini satmak olacaktır.

Topçu \& Gulal (2020) Gelişmekte olan piyasalar üzerinde COVID-19 etkisinin araştırdıkları çalışmada, salgının gelişmekte olan borsalar üzerindeki olumsuz etkisinin kademeli olarak azaldığı ve Nisan ortasına kadar azalmaya devam ettiği sonucuna ulaşılmıştır. Ülkelere ve bölgelere göre bakıldığında ise, Asya'daki yükselen pazarların pandemiden en kötü etkilendiği, Avrupa'da ise sınırlı etkinin olduğu görülmektedir. Çalışmada, ayrıca, pandemi etkisinin, hükümetlerin gerekli önlemleri zamanında aldığı ve daha büyük canlandırma paketlerinin açıklandığı gelişmekte olan piyasalarda nispeten daha az olduğunu belirlenmiştir.

Ashraf (2020) Hükümet tedbirlerinin hisse senedi getirilerine etkilerinin araştırdığ1 çalışmada ise, hükümetlerin sosyal mesafe önlemi uygulamalarının hisse senetlerinin piyasa getirileri üzerinde doğrudan negatif ve dolaylı pozitif etkileri olduğu sonucuna ulaşılmıştır. Çalışmada sosyal mesafe önlemlerinin duyurulmasının ekonomik faaliyetler üzerinde olumsuz etkisinin olacağı beklentisinin hisse senedi piyasa getirilerini negatif etkilediği bulunmuştur. Bununla birlikte söz konusu duyuruların pandemi olgusunu azaltacağı gerekçesiyle piyasa getirilerini pozitif etkilediği sonucuna ulaşılmıştır. Çalışma sonuçlarına göre, benzer şekilde, hükümetlerin farkındalık proğramları, test ve karantina uygulamaları ve gelir destekleme teşvikleri piyasa getirilerini pozitif olarak etkilemektedir.

Baker vd. (2020) COVID-19'un hisse senedi piyasasına etkisi üzerine çalışma sonuçlarına göre, hükümet kısıtlamalarının bireysel hareketlilik ve ticari faaliyet üzerindeki rolü ve gönüllü sosyal mesafe uygulamaları hizmet odaklı bir ekonomide güçlü etkilere sahiptir. Ayrıca günümüz ekonomisinde daha hızlı bilgi yayılımı ve uluslararası tedarik zincirlerindeki aksamaların rolü önemlidir. Yazarlara göre, tedarik zincirleri borsa oynaklığının önemli bir tetikleyicisi olsaydı, Çin ve Avrupa'nın bazı kısımları üretimlerini keskin bir şekilde kısıtlayan sosyal mesafe, karantina ve 
piyasa kapatma önlemleri aldığında, güçlü piyasa tepkileri daha erken gözlemlenmeliydi. Yazarlara göre, uluslararası tedarik zincirlerindeki kesintiler kesinlikle ekonomik faaliyette bir daralmaya katkıda bulunmuş olsa da bunların ABD borsasındaki sıçramaların ve Şubat sonundan bu yana genel piyasa oynaklığının ana nedeni olmadığını göstermektedir.

Mazura vd. (2020) Hisse senedi piyasalarında Mart 2020 düşüşünün araştırdıkları çalışma sonuçlarına göre ise, hisse senedi fiyatlarının düşüşü, tarihin en büyük borsa çöküşlerinden birine işaret etmektedir. Çalışmada, Mart 2020'de borsa çöküş sürecinde sağlık, gıda, doğalgaz ve yazılım sektörlerindeki hisse senetlerinin yüksek getiri sağladığını, buna karşın ham petrol, gayrimenkul, eğlence ve konaklama sektörlerinde önemli ölçüde düștüğü sonucuna ulașılmıștır. Söz konusu firmalar piyasa değerlerinin \%70'inden fazlasını kaybetmişlerdir. Yazarlara göre, kaybeden hisse senetleri daha asimetrik hareketlere sahiptir ve hisse senedi getirileri ile negatif ilişkili olarak aşırı oynaklık sergilemektedir.

Mirza vd. (2020) COVID-19 sürecinde fiyat tepkisi, oynaklık, zamanlama ve fon performansının araştırdıkları çalışmada küresel bir salgının yatırım fonları üzerinde ne gibi etkileri olabileceği araştırılmıştır. Çalışmada, küresel ve finansal stres dönemlerinde yatırımcılar için güvenli bir sığınak sağlayabilecek önceden gözden kaçan yatırım alternatiflerinin önemi vurgulanmaktadır. Çalışmada sosyal girişimcilik fonlarının, özellikle yüksek dalgalanma dönemlerinde yatırım portföylerinde geçerli bir alternatif olarak ortaya çıktığı sonucuna ulaşılmıştır.

Yoshino vd. (2020) COVID-19 ve Sürdürülebilir Kalkınma Hedefleri (SKH) çerçevesinde optimal portföy seçiminin inceledikleri çalışmada, 2030 Sürdürülebilir Kalkınma Gündeminin, başta pandemi ve buna bağlı ekonomik gerileme olmak üzere çeşitli küresel sorunlarla karşı karşıya olduğu vurgulanmaktadır. Küresel durgunluk, yatırımcıları yalnızca getiri oranını ve yatırım riskini dikkate almaya zorlamıştır ve yatırımcılar çevresel faktörlere veya SKH göstergelerine daha az ilgi göstermektedir. Yazarlara göre bu da, COVID-19 sonrası dönemde SKH'lerin başarılarının daha fazla hükümet desteği gerektireceği anlamına gelmektedir. $\mathrm{Bu}$ nedenle, SKH'lere yönelik yatırımları teşvik etmek için kurumsal yatıımcılar tarafından en uygun portföy dağılımını aramak esas olmalıdır. Bu çerçevede SKH doğrultusunda politika değişiklikleri, temiz enerji ve çevreye duyarlı yatırımlar önemli olmaktadır. Özellikle uluslararası vergilendirme sistemi optimal varlık dağglımına ve sürdürülebilir büyümeye ivme kazandırabilecektir. Yazarlara göre, kirlilik yaratan şirketler üzerindeki emisyon vergisi gibi vergiler yeşil projeleri artıracak, bu durum da getiri oranını artıracaktır. Sonuç olarak özellikle bireysel yatırımcıların çevreye duyarlı varlıklara yatırım yapma konusundaki isteklerinde artış olacaktır.

Ortmann vd. (2020) COVID-19 ve yatırımcı davranışı üzerinde çalışmalarında, yatırımcıların kriz dönemlerinde kaldıraç kullanımlarını azalttığı, korkuları nedeniyle daha fazla riskten kaçınan seçimler yaptıkları ifade edilmektedir. Çalışmaya göre bazı yatırımcıların uzun hisse pozisyonları alması, yatırımcıların farklı beklentileri olduğunu vurgulamaktadır. Yazarlara göre, uzun hisse senedi veya endeks pozisyonu alan yatırımcılar, pandemi geçtikten sonra hızlı ekonomik toparlanmanın beklentisini satın almaktadır. Yatırımcıların kısa vadeli ve uzun vadeli beklentileri arasındaki tutarsızlıklar, belirsiz yatırımeı davranışlarına daha fazla katkıda bulunabilmektedir. Çalışma sonuçları, yatırımcıların, COVID-19 salgını ortaya çıkmasıyla birlikte hem kapsamlı hem de yoğun marjda ticaret faaliyetlerini artırdıklarını göstermektedir. Broker ile ilk hesap açan yatırımcı sayısı artarken, aynı zamanda mevcut yatırımcılar da ortalama alım satım faaliyetlerini artırmaktadır. Yazarlara göre, yatırımcılar daha fazla hisse senedi ve endeks pozisyonu açar, ancak güvenli liman (altın) veya özellikle riskli (hisse senetleri, kripto para birimleri) yatırımlara geçmezler. Çalışma sonuçlarına göre günümüz pandemi koşullarında daha önceki belirsizlik yaratan olaylara tezat oluşturacak şekilde, yatırımcılar alım satım yoğunluğunu artırıp daha kolay yeni pozisyonlar açmaktadır. 
Haroon \& Rizvi (2020) Medya haberleri ve finansal piyasa davranışını araştırdıkları çalışma sonuçlarına göre ise, pandemi haberleri yayıldıkça bu durum tüm dünyada paniğe neden olmuş ve finansal piyasalarda oynaklık artışına neden olmuştur. Yazarlara göre, bu süreçte sermaye piyasalarında yatırımcı davranışları tahminler doğrultusunda gerçekleşmektedir.

Azimli (2020) COVID-19'un risk-getiri ilişkisine etkisinin incelendiği çalışmada, değişim bağımsızlığı ve risk-getiri ilişkisinin yapısı açısından COVID-19'a piyasa tepkisinin önceki literatür tarafından belirtilen 2008 krizi ile benzerlikler gösterdiği sonucuna ulaşılmıştır.

Rizvan vd. (2020) COVID-19'un sistematik risk üzerindeki etkisinin araştırdıkları çalışmada, COVID-19'un küresel ekonomiyi yavaşlattığı sonucuna ulaşı1mıştır. Yazarlara göre, finansal kuruluşlar yüksek seviyelerde likidite riski, kredi temerrütleri ve aracılık gelirlerinin kaybı ile karşı karşıyadır. Çalışma sonuçları, çalışmaya dahil edilen ülkeler için COVID-19 döneminde sistemik riskte keskin bir artış olduğunu göstermektedir.

Li vd. (2020) COVID-19 pandemisi ve sermaye düzenlemesinin sigorta şirketlerinin faiz marjı ve yönetim kurulu işlevleri üzerindeki etkilerini araştırdıkları çalışmada, COVID-19 pandemisi ve sermaye düzenlemesinin sigorta sektörünü, optimum garanti oranlarını ve yönetim kurulunun kullanışlılığını artırdığı sonucuna ulaşılmıştır. Çalışma sonuçlarına göre, COVID-19, piyasa oynaklığının birincil gücü olmuştur.

Corbet vd. (2020) Altın ve Kripto para üzerinde COVID-19 etkisinin araştırıdıkları çalışmada hem Şangay hem de Shenzhen Menkul Kıymetler Borsaları göz önüne alındığında, COVID-19'un her bir borsanın oynaklı̆ğ üzerinde güçlü ve önemli bir pozitif etkiye sahip olduğu bulunmuştur. Çalışmada Bitcoin'in fiyat dinamikleriyle ölçülen ne altın ne de kripto para birimlerinin Çin hisse senedi piyasalarıyla önemli bir ilişkiye sahip olmadığ sonucuna ulaşılmıştır. Çalışmada ayrıca Çin piyasalarının pandemi sürecinde oldukça iyi durumda kaldığı vurgulanmaktadır. Bununla birlikte, COVID-19'un coğrafi olarak yayılmasının finansal istikrarsızlık derecesiyle yakından ilişkili olduğunu sonucuna ulaşı1mıştır.

Mnif vd. (2020) COVID-19 sürecinde Kripto Para Piyasasının performansının araştırdıkları çalışmada en iyi beş kripto paranın verimlilik düzeyi incelenmiştir. Çalışmada COVID-19'un kripto para birimi verimliliği üzerindeki etkisi, Magnitude of Long-Memory endeksi kullanarak ölçülmüş̧ür. Çalışma sonuçlarına göre, incelenen tüm kripto para birimleri pandeminin yayılmasından sonra daha verimli hale gelmiştir. Bu süreçte Bitcoin pandemiden önce en verimli iken, pandemiden sonra Ethereum'dan daha az verimlidir.

Salisu vd. (2020) Emtia fiyat getirilerinin COVID-19 ile tahmin edilebilirliğinin araştırıdıkları çalışma sonuçlarına göre, emtia fiyat getirileri ve küresel korku endeksi arasında pozitif ilişki bulunmaktadır. Emtia getirileri pandemi korkusu artışı ile birlikte artmaktadır. Ayrıca OECD hisse senetlerinin performansını değerlendirdiği çalışmada pandemi periodunda, hisse senedi getirileri ve global korku endeksi arasında negatif ilişki hesaplanmıştır. Çalışma sonuçlarına göre kriz ve tirbülans dönemlerinde emtialar, hisse senedi piyasalarının düşüşüne ve oynaklığına karşı hedge rolü oynamaktadır.

Sharif vd. (2020) Petrol fiyatları ve hisse senedi piyasalarında coğrafi riskin COVID-19 çerçevesinde analiz ettikleri çalışma sonuçlarına göre, COVID-19 salgını ekonomik bozulmaya, ABD ekonomi politikası belirsizliğinde olağanüstü bir artışa ve borsada benzeri görülmemiş bir tepkiye neden olmaktadır. Yazarlara göre petrol dalgalanma şokları, OPEC anlaşmalarıyla bastırılabilecek geçici bir risk olarak algılanabilirken, COVID-19 krizi, pandemi sırasında dünya çapında seyahat kısıtlamaları nedeniyle petrol fiyatını daha da etkileyebilir. Bu sonuç sadece petrol arama ve üretim şirketleri için değil, ulaşım ve konaklama sektörlerindeki şirketler ile petrol fiyatı ve emtia türevlerine duyarlı hisse senetlerinde yatırımı olan yatırımcılar için de önemlidir. 
Çalışmaya göre, ABD borsasını sarsan sistematik bir risk olarak COVID-19'un yayılması, ekonomik politika belirsizlik endekslerini muazzam seviyelere yükseltmiştir.

Gharib vd. (2020) COVID-19'un petrol ve altın piyasalardaki büyümeye etkisinin araştırdıkları çalışmada, COVID-19 pandemisi sırasında petrol ve altın piyasalarında genişlemenin olası etkileri tespit edilmeye çalışılmıştır. Özellikle petrol fiyatları ile diğer emtia fiyatları da dahil olmak üzere genel ekonomik aktivite arasındaki bağlantı tespit edilmiştir. Yazarlara göre söz konusu bağlantılar, aynı zamanda, farklı piyasa katılımcıları için de geçerlidir (fiyat değişiklikleri tahminleri, portföy çeşitliliği, çapraz riskten korunma ve çapraz spekülasyon).

Bartik vd. (2020) Küçük işletmeler üzerinde pandemi etkisinin araştırdıkları çalışmada ise, ABD'de birçok küçük işletmenin mali kırılganlığı ve mevcut krizden derinden etkilendiği vurgulanmaktadır. Çalışma sonuçlarına göre, perakende sektöründe, işletmelerin \%43'ü geçici olarak kapanmış ve işsizlik \%40 düşmüştür. Yazarlara göre, pandeminin başlangıcında bu firmaların çoğunda çok az nakit bulunmaktadır, bu durum da ya masrafları önemli ölçüde kısmaları, ek borç almaları ya da iflas etmeleri anlamına gelmektedir.

\section{3.Çalışmanın Amacı, Kapsamı ve Yöntemi}

Çalışmada COVID 19 Pandemisinin BİST üzerindeki etkisi İmalat sektörü özelinde araştırılması amaçlanmıştır. Bu kapsamda 6 Eylül 2019-22 Eylül 2020 tarihleri arasında BİST 100 'de işlem gören imalat sektörüne ait 39 adet hisse senedi belirlenmiştir. Çalışmada Ülkemizde ilk vakanın duyurulduğu 11 Mart 2020 tarihi baz alınmış ve bu tarihten bir gün öncesi, bir gün sonrası ve duyuru tarihi gün bazında, duyuru tarihi öncesi 130 gün ve duyuru tarihi sonras1 130 gün süreç bazında incelenmiştir. Çalışmada incelenen periyotta hisse senetlerinin getiri üretip üretemedikleri araştırılmıştır. Çalışmada ulaşılan sonuçlara gün ve süreç bazında t testi ile anlamlılık testi yapılmıştır. T testi kullanılmasındaki amaç ortalama getiri farklılıklarını tespit edebilmektir. Çalışmada hisse senedi getiri hesaplamalarında aşağıdaki formül kullanılmıştır:

Hisse Senedi Getirisi \%= (Cari Gün Hisse Senedi Kapanış Fiyatı - Bir Önceki Gün Hisse Senedi Kapanış Fiyatı) / Duyuru Tarihi Hisse Senedi Kapanış Fiyatı

Çalışmanın Hipotezleri:

Fiyat Hipotezleri

H 0: duyuru tarihinden önceki ve sonraki süreçte hisse senedi getirileri arasında istatistiksel olarak anlamlı bir farklılık bulunmamaktadır

H 1: duyuru tarihinden önceki ve sonraki süreçte hisse senedi getirileri arasında istatistiksel olarak anlamlı bir farklılık bulunmaktadır 
Tablo 1: Hisse Senedi Getiri Verileri

\begin{tabular}{|c|c|c|c|c|c|}
\hline Hisse Senedi & Dt-130 & Dt-1 & Dt & Dt+1 & $\mathrm{Dt}+\mathbf{1 3 0}$ \\
\hline akçansa & 0,26 & $-0,01$ & $\begin{array}{c}-0,02 \\
\end{array}$ & $-0,08$ & 0,72 \\
\hline Aksa & 0,26 & $-0,02$ & $-0,04$ & $-0,02$ & 0,19 \\
\hline Arçelik & $-0,02$ & 0,00 & $-0,02$ & $-0,08$ & 0,40 \\
\hline Aygaz & 0,06 & 0,01 & $-0,01$ & $-0,07$ & 0,10 \\
\hline Bagfas & 0,07 & $-0,07$ & $-0,02$ & $-0,09$ & 0,46 \\
\hline Brsan & $-0,04$ & $-0,07$ & $-0,04$ & $-0,11$ & 0,70 \\
\hline Brisa & 0,24 & $-0,05$ & $-0,02$ & $-0,01$ & 0,56 \\
\hline Buçim & 0,12 & $-0,05$ & $-0,02$ & $-0,09$ & 0,93 \\
\hline Ccola & 0,13 & 0,02 & $-0,03$ & $-0,08$ & 0,10 \\
\hline Cemtaş & 0,02 & $-0,04$ & 0,02 & $-0,12$ & 1,31 \\
\hline Çimsa & 0,17 & $-0,02$ & $-0,05$ & $-0,11$ & 0,62 \\
\hline Deva & 0,18 & $-0,07$ & 0,17 & 0,07 & 0,92 \\
\hline Doco & $-0,39$ & $-0,06$ & $-0,06$ & $-0,12$ & $-0,17$ \\
\hline Egeen & 0,10 & $-0,07$ & $-0,04$ & $-0,04$ & 0,45 \\
\hline Ereğli & 0,24 & 0,02 & $-0,02$ & $-0,04$ & 0,12 \\
\hline Frtoto & 0,19 & $-0,05$ & $-0,01$ & $-0,06$ & 0,34 \\
\hline Goodyr & 0,27 & $-0,09$ & $-0,02$ & $-0,13$ & 0,29 \\
\hline Gurfb & 0,70 & $-0,09$ & 0,05 & $-0,10$ & 0,77 \\
\hline Hektaş & 0,33 & $-0,01$ & 0,01 & $-0,01$ & 0,40 \\
\hline İsdmr & 0,13 & $-0,02$ & $-0,04$ & $-0,05$ & 0,08 \\
\hline Kard & 0,09 & $-0,08$ & $-0,03$ & $-0,08$ & 0,50 \\
\hline Karsan & 0,28 & $-0,10$ & 0,02 & $-0,18$ & 0,87 \\
\hline Kartn & 0,04 & $-0,07$ & $-0,04$ & $-0,09$ & 1,19 \\
\hline Kerevit & 0,18 & $-0,09$ & 0,06 & $-0,04$ & 0,67 \\
\hline Klmsan & 0,31 & $-0,01$ & 0,03 & $-0,04$ & $-0,16$ \\
\hline Kordsa & $-0,06$ & $-0,04$ & $-0,01$ & $-0,09$ & 0,03 \\
\hline Kçhol & $-0,11$ & $-0,03$ & $-0,07$ & $-0,05$ & $-0,10$ \\
\hline Otokar & 0,02 & $-0,05$ & $-0,05$ & $-0,05$ & 0,17 \\
\hline oyakçim & 0,47 & $-0,01$ & 0,00 & $-0,01$ & 0,49 \\
\hline Petkim & $-0,07$ & $-0,01$ & $-0,02$ & $-0,08$ & 0,29 \\
\hline Sasa & 0,14 & $-0,08$ & $-0,01$ & $-0,15$ & 1,40 \\
\hline Soda & $-0,09$ & $-0,03$ & $-0,05$ & $-0,06$ & 0,57 \\
\hline Tatgd & 0,18 & $-0,02$ & 0,08 & $-0,09$ & 0,59 \\
\hline Toaso & 0,20 & 0,00 & $-0,01$ & $-0,06$ & 0,13 \\
\hline Tmsn & 0,17 & $-0,08$ & $-0,06$ & $-0,16$ & 0,57 \\
\hline Tüpraş & $-0,44$ & $-0,02$ & $-0,03$ & $-0,06$ & $-0,11$ \\
\hline Ttrak & 0,26 & $-0,08$ & $-0,03$ & $-0,06$ & 1,03 \\
\hline Ülker & 0,07 & $-0,06$ & 0,03 & $-0,07$ & 0,09 \\
\hline Yataş & 0,10 & 0,00 & $-0,08$ & $-0,11$ & 0,35 \\
\hline Topl. Getiri\% & 4,74 & $-1,63$ & $-0,51$ & $-2,88$ & 17,87 \\
\hline $\begin{array}{l}\text { Ort. Topl. } \\
\text { Getiri\% }\end{array}$ & 0,12 & $-0,04$ & $-0,01$ & $-0,07$ & 0,46 \\
\hline
\end{tabular}


Dt-130: duyuru tarihinden 130 gün öncesi, Dt-1: duyuru tarihinden 1 gün öncesi, Dt: duyuru tarihi,

Dt+1: duyuru tarihinden 1 gün sonrası, Dt+130: duyuru tarihinden 130 gün sonras1

Tablo 1 hisse senedi getiri sonuçlarına göre, BİST 100 de işlem gören İmalat sektörüne ait hisse senetlerinin gün bazında ortalama olarak negatif getiri ürettikleri görülmektedir. Söz konusu getiri duyuru tarihinden bir gün sonrasinda daha belirgindir $(\mathrm{Dt}+1:-0,07)$. Bu tarihte pandemi etkisiyle Dünya borsalarında görülen düşüşe paralel BİST'te de düşüş gerçekleşmiştir. Araştırmada pandeminin yarattığı belirsizlik ortamında özellikle Duyuru tarihi etrafında fiyat oynaklığının yüksek olduğu gözlemlenmiştir. Tablo verileri süreç bazında incelendiğinde duyuru tarihinden 130 gün önceki süreçte (Dt-130) ortalama olarak \%0,12, duyuru tarihinden sonraki 130 günlük süreçte $(\mathrm{Dt}+130)$ ortalama olarak \%0,46 pozitif getiri ürettiği görülmektedir. Ulaşılan sonuçlar istatistiksel olarak da anlamlıdır (Tablo 2). Bu verilere göre BİST 100 de işlem gören imalat sektörü hisse senetlerinin pandemiden önceki süreçten daha fazla getiri ürettikleri görülmektedir. Bu veriler BISST bazında sektörün pandeminin olumsuz etkilerini giderdiği ve toparlandığı şeklinde yorumlanmaktadır. Bu sonuçlara göre H 1: duyuru tarihinden önceki ve sonraki süreçte hisse senedi getirileri arasında istatistiksel olarak anlamlı bir farklılık bulunmaktadır hipotezi kabul edilmektedir.

Tablo 2: T Testi

\begin{tabular}{|c|c|c|c|c|c|c|}
\hline & & $\mathrm{N}$ & Ortalama & Std. Sapma & $\mathrm{t}$ & $\mathrm{p}$ \\
\hline \multirow[t]{2}{*}{ Analiz 1} & a1 & 39 & 0,122 & 0,200 & $-5,431$ & $0,000 *$ \\
\hline & a5 & 39 & 0,458 & 0,398 & & \\
\hline \multirow[t]{2}{*}{ Analiz 2} & a2 & 39 & $-0,041$ & 0,034 & $-2,895$ & $0,006^{*}$ \\
\hline & a3 & 39 & $-0,012$ & 0,046 & & \\
\hline \multirow[t]{2}{*}{ Analiz 3} & $\mathrm{a} 2$ & 39 & $-0,041$ & 0,034 & 4,194 & $0,000 *$ \\
\hline & $\mathrm{a} 4$ & 39 & $-0,074$ & 0,046 & & \\
\hline \multirow[t]{2}{*}{ Analiz 4} & $\mathrm{a} 2$ & 39 & $-0,041$ & 0,034 & $-7,490$ & $0,000 *$ \\
\hline & a5 & 39 & 0,458 & 0,398 & & \\
\hline \multirow[t]{2}{*}{ Analiz 5} & a3 & 39 & $-0,012$ & 0,046 & 7,422 & $0,000 *$ \\
\hline & $\mathrm{a} 4$ & 39 & $-0,074$ & 0,046 & & \\
\hline \multirow[t]{2}{*}{ Analiz 6} & a3 & 39 & $-0,012$ & 0,046 & $-7,564$ & $0,000 *$ \\
\hline & a5 & 39 & 0,458 & 0,398 & & \\
\hline \multirow[t]{2}{*}{ Analiz 7} & $\mathrm{a} 4$ & 39 & $-0,074$ & 0,046 & $-8,067$ & $0,000 *$ \\
\hline & a5 & 39 & 0,458 & 0,398 & & \\
\hline
\end{tabular}

\section{Sonuç}

Çalışma sonuçlarına göre ilk vakanın duyurulması ile birlikte sektörde günlük bazda satış gerçekleşmekle birlikte süreç bazında zaman ilerledikçe toparlanmanın olduğu gözlenmektedir. Süreç bazında toparlanma ilk vaka duyurusunun olduğu günden sonraki 130 günlük süreçte $(\mathrm{Dt}+130)$ ortalama olarak \%0,46, önceki 130 günlük süreçten (Dt-130) ortalama olarak \%0,12, daha fazla olarak ölçülmüştür. Bu noktada pandemi sürecinde piyasaya katılan yeni yatırımcıların BİST 100 İmalat sektörü hisse senetlerine taleplerinin etkili olduğu düşünülmektedir. Ayrıca sektör hisse senetlerinin derinliği olan güçlü hisseler oluşunun da etkili olduğu söylenebilir. Yatırımcı risk iştahı da bir diğer önemli faktör olarak değerlendirilmektedir. Ek olarak, COVID 19 sürecinde piyasalara aktarılan fonların hisse senedi piyasasına yöneldiği söylenebilir. Bunun da imalat sektörü hisse senetlerinin performansında etkili olduğu düşünülmektedir. Bununla birlikte borsalarda toparlanma ile birlikte belirsizlik ortamı da devam etmekte, bu durum da borsaların yükselmesini 
engellemektedir. BİST'ten yabancı yatııımcı çıkışı artmakta, bu noktada ekonomi politikalarının sürdürülebilir olması, özellikle yabancı yatırımcılarda güven sağlayarak doğrudan ve portföy yatırımlarını artırmak gerekmektedir.

Genel olarak Ekim ayı itibariyle piyasalarda olumlu bir sürecin olduğu söylenebilir. Bununla birlikte, birlikte döviz kurlarındaki artışın etkisiyle enflasyon artmakta, TL'nin değer kaybı ithalat ihracat dengesini olumsuz etkilemekte, üretim girdi maliyetlerini artırıcı etki yapmaktadır. Ayrıca, ikinci dalga beklentileri piyasalarda belirsizlik oluşturmaktadır. Dolayısıyla, yaşanan olumlu ekonomik süreç iyileşme olarak tanımlanmakta, normalleşme için erken olduğu düşünülmektedir. Genel olarak pandemi sürecinde ülkelerin ihracat gelirlerinde azalma olduğu söylenebilir. Küresel ölçekte ekonomilerin olumsuz etkilendiği bir süreçte ihracat yapabilmek zorlaşmaktadır. Dolayısıyla yeni yapılacak teknoloji yoğun yatırımlarla marka değeri yüksek ürünler üretilerek ihracatın artırılması gerekmektedir. Ayrıca güçlü bir ekonomi için enerjide dışa bağımlılığı azaltmak da önemli bir unsur olarak değerlendirilmektedir. Bu noktada yeni keşfedilen enerji rezervlerinin sektörü ilerleyen süreçte olumlu etkileyeceği düşünülmektedir. Benzer şekilde, COVID-19 pandemisi nedeniyle ülkelerin ulaştırmadaki kısıtlamaları nedeniyle tedarik zincirleri olumsuz etkilenmekte, dolayısıyla, uluslararası kısıtlamaların azaltılmasının sektörü olumlu etkileyeceği açıktır.

İmalat sektörü hisse senetleri performansı PMİ verileri çerçevesinde değerlendirildiğinde, COVID-19 etkisiyle Nisan, Mayıs ve Haziran aylarında daralma yaşanan sektör PMİ (bmd.com.tr, 2020), Temmuz ve Ağustos, (bloomberght.com, 2020) verilerinin olumlu olmas1 nedeniyle ekonominin genel olarak büyüme performansı sergileyeceğini göstermektedir. Ayrıca sektörde kapasite kullanım oranı Ağustos’ta \%73,3, Eylül'de \%74,6 olarak gerçekleşmiştir (tcmb, 2020). Açıklanan veriler sektörün pandeminin olumsuz etkilerinin azalttığı, istihdam ve büyüme sağladığı, dolayısıyla iyileşmeye devam edeceği şeklinde yorumlanmaktadır. Bu durumun da sektör hisse senetlerinin performansını olumlu etkileyeceği açıktır.

Türkiye ekonomisini hızla bu kriz ortamından çıkartarak küresel tedarik zincirinin bir parçası haline getirmek gelecekteki firsatları yakalamak açışından önemli görülmektedir (21yyte.org). Bu çerçevede pandeminin yaratabileceği uluslararası talep kaymaları ve tedarik zincirlerindeki değişimden Türkiye için firsatlar oluşması Dış Ticaret Dengemizi olumlu etkileyebilecektir (Adıgüzel, 2020). Özellikle İmalat sanayii şirketleri için krizden çıkışın V şeklinde olacağını söyleyebiliriz. Çünkü bu sektörlerde talep büyük ölçüde ötelenecek ve kriz sonrasında geri dönecektir (Şahbaz, 2020). Türkiye içinde bulunduğumuz bu durumu firsata çevirebilecek bir potansiyele sahiptir. Avrupalı otomotiv üreticilerinin, lojistik alanındaki sıkıntıları görerek daha çok Türkiye gibi yakın bölgelerdeki tedarik sanayisine yöneleceklerini öngörüyoruz. Çin'e alternatif bir tedarik sanayisi yaratmak için en elverişli ülkelerden biri olduğumuzu söyleyebiliriz (Ölekli, 2020). Pandemi süreci Türkiye için bir avantaj da yaratmış olduğu söylenebilir. Küresel ara mal tedarik altyapısının ve alternatifsiz konumdaki Çin'in ciddi olarak sorgulanmaya başlaması, orta ve uzun vadede tekstil sektörü gibi alanlarda ön plana çıkmak isteyen Türkiye adına önemli bir avantaj yaratmaktadır. Tedarik zincirinin çeşitliliğinin ne derece önemli olduğunun anlaşılmasıyla, ara malı talebinde öne çıkan birçok üründe üretim çeşitliliğini ve dönüşümünü sağlamada yetkin hale gelmiş Türkiye, en önemli alternatif olarak ön plana çıkmıştır. Türkiye, dinamik ve rekabetçi özel sektörünün yanında sürdürülebilir borç stoku, dinamik bir iç pazarı ve en önemlisi kalifiye genç insan kaynağı ile salgın sonrası dönemin önemli aktörlerinden biri olmaya adaydır (Yorulmaz ve Kaptan, 2020).

Sektörün toparlanma sürecinde olduğu göz önünde bulundurulduğunda, araştırmacılara, ilerleyen süreçte, pandeminin uzun vadeli etkisinin araştırılması ve özellikle bireysel yatırımcılara kısa vadeden ziyade orta ve uzun vadeli yatırım yapmaları önerilmektedir. Ayrıca, hisse senetleri satın alınırken gerçek değerinin ve büyüme potansiyelinin analiz edilmesi gerekmektedir. Hisse 
senetlerinin kalitesi, taşıdığı riskler ve geçmiş performansları önemli birer unsur olarak göz önünde bulundurulmalıdır.

\section{Kaynakça}

Adıgüzel, M., (2020). COVID-19 Pandemisinin Türkiye ekonomisine etkileri makroekonomik analizi. İstanbul Ticaret Üniversitesi Sosyal Bilimler Dergisi Covid-19 Sosyal Bilimler Özel Saylst, Y1l:19, Say1:37, Bahar (Özel Ek), 191-221 https://dergipark.org.tr/tr/download/article-file/1166150

Ali, M., Alam, N. \& SAR, R. (2020). Coronavirus (Covid-19)-An epidemic or pandemic for financial markets. Journal of Behavioral and Experimental Finance 27, 1-6. https://doi.org/10.1016/j.jbef.2020.100341

Altin, H., (2020). Efficient Market Hypothesis for Islamic Capital Markets. Handbook of Research on Theory and Practice of Global Islamic Finance, 489-523. https://doi: 10.4018/978-17998-0218-1.ch027

Ashraf, B.N., (2020). Economic impact of government interventions during the COVID-19 pandemic: International evidence from financial markets. Journal of Behavioral and Experimental Finance, Volume 27, 1-9. https://doi.org/10.1016/j.jbef.2020.100371

Azimli, A. (2020). The impact of Covid-19 on the degree of dependence and structure of risk-return relationship: A guantile regression approach. Finance Research Letters, 1-5. https://doi.org/10.1016/j.frl.2020.101648

Baker, S.R., Bloom, N., Davis, S.J., Kost, K.J. \& Sammon, M.C. (2020). The unprecedented stock market impact of COVID-19. NBER Working Paper No. 26945, 1-24. https://www.nber.org/papers/w26945.pdf

Bartik, A. W., Bertrand, M., Cullen, Z., Glaeser, E.L., Luca, M. \& Stanton, C. (2020). The impact of COVID-19 on small business outcomes and expectations. PNAS, 17656-17666 https://www.pnas.org/content/pnas/117/30/17656.full.pdf

Corbet, S., Larkin, C. \& Lucey, B. (2020). The contagion effects of the Covid-19 pandemic: Evidence from gold and crypto currencies. Finance Research Letters, 1-7. https://doi.org/10.1016/j.frl.2020.101554

Gharib, C., Mefteh-Wali, S. \& Jabeur, S.B. (2020). The bubble contagion effect of Covid-19 outbreak: Evidence from crude oil and gold markets. Finance Research Letters, 1-10. https://doi.org/10.1016/j.frl.2020.101703

Goodell, J. W. (2020). COVID-19and finance: Agendas for future research. Finance Research Letters 35, 1-6. https://doi.org/10.1016/j.frl.2020.101512

Haroon, O. \& SAR, R. (2020). Covid-19: Media coverage and financial markets behavior-A sectoral inquiry. Journal of Behavioral and Experimental Finance 27, 1-5. https://doi.org/10.1016/j.jbef.2020.100343

Li, X., Lin, P. \& Lin, H. (2020). COVID-19, Insurer Board utility, and capital regulation. Finance Research Letters, 1-6. https://doi.org/10.1016/j.frl.2020.101659

Liu, H.Y., Manzoor, A., Wang, C.Y. \&, Zhang, L. (2020). The Covid-19 outbreak and affected countries stock markets response. International Journal of Environ. Res. Public Health, 17(8), 1-19. https://doi.org/10.3390/ijerph17082800 
Mazura, M., Dang, M. \& Vega., M. (2020). Covid-19 and the march 2020 stock market crash: Evidence from S\&P1500. Finance Research Letters, 1-8. https://pdf.sciencedirectassets.com/273054/AIP/

McKibbin, W. \& Fernando, R. (2020). The global macroeconomic impacts of Covid-19: Seven scenarios. CAMA Working Paper 19, February, 1-45. file:///C:/Users/user/AppData/Local/Packages/Microsoft.MicrosoftEdge_8wekyb3d8bbwe/ TempState/Downloads/SSRN-id3547729\%20(1).pdf

Mirza, N., Naqvi, B., Rahat, B. \& Rizvi S.K.A. (2020). 'Price reaction, volatility timing and funds' performance during Covid-19. Finance Research Letters, 1-8. https://doi.org/10.1016/j.frl.2020.101657

Mnif, E., Jarboui, A. \& Mouakhar, K. (2020). How the crypto currency market has Performed during Covid-19? A Multifractal analysis. Finance Research Letters, 1-14. https://doi.org/10.1016/j.frl.2020.101647

Nicola, M., Alsafi, Z., Sohrabi, C., Kerwan, A., Al-Jabir, A., Losifidis, C., Ağha, M. \& Ağha, R. (2020). The socio-economic implications of the coronavirus pandemic (COVID-19): A review. International Journal of Surgery, Jun: 78, 185-193. https://doi:10.1016/j.ijsu.2020.04.018

Ortmann, R., Pelster, M. \& Wengerek, S.T. (2020). Covid-19 and investor behavior. Finance Research Letters, 1-9. https://pdf.sciencedirectassets.com/273054/AIP/Expires=300\&hash=fde09bf6bdfe31fb04a 281156a2578f088996351aa1e9bffe30023b28965857a

Ramelli, S. \& Wagner, A.F. (2020). Feverish stock price reactions to COVID-19. Discussion Paper DP14511, 1-61. https://repec.cepr.org/repec/cpr/ceprdp/DP14511.pdf

Rizwan, M. S., Ahmad, G. \& Ashraf, D. (2020). Systemic risk: The impact of Covid-19. Finance Research Letters 36, 1-7. https://pdf.sciencedirectassets.com/273054/

Salisu, A., Akanni, L. \& Raheemc, I. (2020). The Covid-19 global fear index and the predictability of commodity price returns. Journal of Behavioral and Experimental Finance, Volume 27, 1-7. https://doi.org/10.1016/j.jbef.2020.100383

Sharif, A., Aloui, C. \& Yarovaya, L. (2020). Covid-19 pandemic, oil prices, stock market, geopolitical risk and policy uncertainty nexus in the US economy: Fresh evidence from the wavelet based approach. International Review of Financial Analysis 70, 1-9. https://doi.org/10.1016/j.irfa.2020.101496

Topcu, M. \& Gulal, O. S. (2020). The impact of Covid-19 on emerging stock markets. Finance Research Letters, 1-4. https://doi.org/10.1016/j.frl.2020.101691

Yorulmaz, R., Kaptan, S., (2020), Kovid-19 ile mücadele sürecinde maliye politikalarının rolü. $\begin{array}{lllll}\text { ULISA } & 12, & \text { Say1 24-30. }\end{array}$ https://aybu.edu.tr/yulisa/contents/files/ULISA12_Kovid_19_Ekonomik_Etkiler.pdf

Yoshino, N., Taghizadeh, F. \& Otsuka, M. (2020). Covid-19 and optimal portfolio selection for investment in sustainable development goals. Finance Research Letters, 1-6. https://doi.org/10.1016/j.frl.2020.101695

Zhang, D., HU, M. \& Ji, O. (2020). Financial markets under the global pandemic of Covid-19. Finance Research Letters 36, 1-6. https://doi.org/10.1016/j.frl.2020.101528 


\section{İnternet Kaynakları}

Ölekli, H., https://www.haberturk.com/turkiye-salgini-firsata-cevirebilir-haberler-2680235ekonomi (Erişim Tarihi: 09.11.2020)

Şahbaz, U., Korona'nın Türk Ekonomisine Sunduğu Firsatlar, 1 Nisan 2020, https://www.perspektif.online/koronanin-turk-ekonomisine-sundugu-firsatlar/ (Erişim Tarihi: 09.11.2020)

https://www.bloomberght.com/turkiye-imalat-pmi-temmuz-2261413 (Erişim Tarihi: 23.09.2020)

https://finans.mynet.com/borsa/hisseler/tarihselveriler/ (Erişim Tarihi: 1-23.09.2020)

https://www.tcmb.gov.tr/wps/wcm/connect/9c32cdb1-30ba-467b-9cf5-30b05fca38a7/KKO-

Rapor.pdf? (Erişim Tarihi: 02.10.2020)

https://www.21yyte.org/tr/koronavirus-salgini/koronavirus-krizi-sonrasi-gelismeler-turkiyeacisindan-firsatlar (Erişim Tarihi: 09.11.2020)

https://bmd.com.tr/page/rapor_detay/4273/imalat-sanayi-pmi-temmuz-2020.htm (Erişim Tarihi: 23.09.2020) 